\title{
Mayavini Sarsi (Circe): Devkota's Reworking to Western Myths
}

\author{
Keshav Raj Chalise \\ Lecturer in English, \\ Nepal Sanskrit University, Nepal
}

\section{Introduction}

Laxmi Prasad Devkota, celebrated poet as the Mahakavi or Poet the Great wasborn in 1966 BS. Writing in distinct style from the tradition, Devkota has broken the convention in Nepalese writing, both in form and content, though he was in the difficult mode of free expression due to Rana observation over writings and even the discouraging situation on free thinking and creative writing.

He has adapted Sanskrit tradition of writing epics, (Mahakavya) and also, he has composed the epic on free verse. He has introduced and applied western Romantic trend of writing poetry. With these new modes, he has introduced new genre and approach in writing poems and other forms of literature. Openness, lucidity and honesty are some of the characteristics of Devkota's poetic works. His feelings, sensibility and expressions have been blended perfectly and brilliantly with words and meanings that have created an explosion of thoughts and ideas in his writings. We find spontaneous expression in his poems and there is no artificial sense.

As a versatile writer, he has composed in all literary genres, pomes, epics, essays, plays and fictions, but he is basically a poet. Having with the knowledge both in eastern Sanskrit literature and western literary traditions, he has combined both traditions in his Nepali writings. With the use of the western and eastern mythical references, he has united the traditions of the both in his writings. This article aims to observe his revisit to the eastern and western mythical references in Mayavini Circe, the epic on free verse.

\section{Myths: An Endless Course}

'Myth' is a derivative term from Greek 'mythos' signifying any story or plot with equal possibility of true or made up quality. It is a term of "complex history and meaning"(Cuddon 525). In the modern perception, "a myth is one story in a mythology"(Abraham 178). Mythology is an umbrella concept embodying many stories of ancient or religious origin that are believed to be true in any particular cultural and social group. Basically, such stories explain directly or indirectly about the origin of the world and provide certain system of social and cultural customs intended to regulate the social life. Most of the stories on myth are based on rituals however the modern anthropologists have argued to explain, "whether rituals generated myths or myths generated rituals"(178). They are supposed to be the products of rituals reflecting the culture of social group because they are distinct from one culture/ religion to another.

Homer uses 'muthos' to mean narrative and conversation but not a fiction. In ancient Greece, it is usually used to mean fiction however "Plato refers to 'muthoi' to denote something not wholly lacking truth"(Cuddon 525). The perceptions and 
definitions of myth move from mere fictive views to more realistic aspects up to the modern interpretation. Levi Strauss, Norton Frye, Carl Jung and Frazer define the myth in a quite new perspective as the logic of the search of reality of the world. Frazer makes an attempt to explain myth with reference to rituals designed to ensure the continuing fertility and vegetable life whereas Frye assigns "all myths to an appropriate place in the cycle of seasons"(Childs and Roger 146). Strauss tries to explain the essence of myths on the structural level and Jung relates myths with psychological interpretation.

The ancient mode of looking at myths just as the stories on religion, of gods and rituals changes into the way of seeing the truth in certain acuity of culture though they come across from the very primitive time. Many myths are "primitive explanations of natural order and cosmic forces"(Cuddon 526). They provide intuition to the explanation and understanding of the truth though they may not be the ends of the explanation in themselves.

Despite having these distinct patterns of myths, they have commonalities that stories of myth have "apparent universality and timelessness"(Childs and Roger 146). They are not geographically limited and bound to within certain time. They have spontaneity and collectivity expressing generally satisfying account of human experiences with lasting impacts on the human civilization. The modern analyses of myths have more logics. These have the concepts that myths are the plots, narratives and fiction of and about the gods and legendry heroes, but also they are the experiences of humans through which "a given culture ratifies its social customs or the accounts for the origins of human and natural phenomena" (Baldick 163). So, the explanations about the origin of the world, human life and universal nature are areas of the myths and their interpretations.'Myth' has a wide range of meanings, which can be divided roughly into "rationalist and romantic versions"(163). In the first, a myth is a false or unreliable story or belief that is mythical. In the second, "myth is a superior, intuitive mode of cosmic understanding" (163) that is mythic.

Hence, myth, usually as an anonymous story, and rooted in the primitive people's faith, presents somehow supernatural episodes to explain natural events and phenomena. Myths, as the combination of many mythical stories or episodes, attempt to interpret and explain a creation, divinity, and religion. They explain the meaning of existence and death. They account for the natural phenomena and the adventures of racial and other heroes. Myths, as the products of any racial or tribal or religious group from any moment of past, are not created out of nothing;but they are always the covering, the shell, to a grain of truth contained inside, the content with certain theme or subject to deliver.Almost with no exact point of origin, and some with the reference of historicity, myths pass throughout the history endlessly, however revision, formation and reformation, interpretation and reworking with the existing myths are regular processes. Myths have some contexts, some historicity, some fact, some belief and mostly the mode of literature both in form and content.

\section{Myth and Literature}


Myth and literature exist both autonomously and dependently though it appears quite paradoxical. It becomes a justice to understand literature and myth with mutual dependence with autonomy of existence. Literature cannot be only the myth and myth cannot be only literature. Myth survives in literature and it gives the shape to the literature, and even the content to deal with, as "literature itself is mythopoeic" (Bell 119 ) and "it creates myth as a life form" (119). Myth gives the field for the creation of literature and literature creates myth. This sense of the acceptance of each other's existence leads to the mutual dependence between literature and myth.

Myth offers a storehouse of manifold stories for the fictional world making of literature. It expands, modifies, or rewrites mythological elements in the process of creative reception, and also it provides the narrative approaches which literature evolves from. Mythos refers to plot, to a unified construct of required and probable actions. Furthermore, as suggested by the etymology of mythos, 'word', myth epitomizes the very origin of literature, which is rooted in oral tradition and the performance of literary texts. Literature is understood as the body of texts that have entered into writing or printing, which allows for a first variation between literature and myth, and it has emerged from story telling. Rooted in oral tradition, myth has its own mode of expression and also it depends on its translation into other forms, primarily art and literature to preserve and continue its imagery as well as its knowledge, and it transfers itself in different cultural, geographical, and temporal space.

Myth becomes readable only through the literature, however it exists in oral form even without its transformation in the written form. The understanding of mythological elements, hence, ultimately involves the re-entering into a literary dimension where they become "readable" and intelligible. Literature, therefore, performs as the supreme instrument for the transportation of mythical stories, "literary texts are read as the creative reworking of myths" (Buchanan 329). Thus, literature is not only constituted by, but also constitutive for the communication of myth.

Even though the differentiation of literature and myth is not unproblematic insofar as myth cannot exist outside literature while literature does not collapse in myth, the conflation of the two dismisses their different connection to knowledge, which is nonetheless very significant for a closer analysis of the knowledge of literature. It greatly relies upon, yet cannot be reduced, to the knowledge of myth. Hence, myths have their origin, pattern and the stories to tell, and literature has a separate pattern, mode of expression, and still these two disciplines unite in one for the purpose of generating, encouraging and transmitting knowledge from past to present and from present to future, generations to come.

\section{Devkota and Myth}

Known and eminent as the Mahakavi, LaxmiPrasad Devkota has contributed immense literary property to Nepali literature, "of the books he wrote, fifty five in Nepali and four in English have been published so far. A minimum of six books in Nepali and three in English have yet to be published" (Devkota, Padma xx-xxi). Influenced by the eastern mythical Sanskrit texts and western mythical English texts, and having the good knowledge in English, Devkota has numerous translations and the writings combined with rich mythical references, and "what really lifts him to literary 
eminence is the quality of his works: the vision, the imagination and the mastery over the language which he molded and shaped into excellent literary forms"(xxi). His ability to write in varieties of themes, ability to mold the existed matters in the unique form, creative imagination and the ability to transfer wider themes of the world literature into Nepalese context have enabled him to uplift himself at the point of poet the great.

One of the major modes of Devkota's creation was his excellence on myth making and mythical reworking in his writings as "his eyes were on the major myths and cultures of the world" (xxi). Having studied western mythical books, he has composed Promithas, Mayavini Circe and Sundari Proserpina based on the Greek mythical references. Similarly, Shakuntala, having the theme of Hindu mythical story of Shakuntala, Sita Haran, story based on Ramayana myth, and RavanJatayuYuddha, "with the story of Ravan and Jatayu conflict from Ramayana" (Joshi 188), have projected his careful handling of eastern Hindu mythical stories, though variation in the structure and even the plot exists with reasonable style in each. Also he has properly depicted the local and racial mythical stories through Kunjini, Luni and Mhendu. These texts have presented the mythical and cultural life style of the people from different caste and racial cultures.PrithivirajChaauhan is an example of his understanding on Indian history in which he has dealt with 'the theme of the life and priority of Hindu Kingship of PrithivirajChauhan, the king of Delhi and Ajmer" (Joshi 186).

Hence, Devkota has composed many of his creations grounding on varying mythical themes. He plays with myths, molds and gives newness in the mythical themes with the native savor. Not only in his epics, but also, he has used mythical references in his individual poems perfectly.

\section{Mayavini Sarsi (Circe): A Quick Survey of the Plot}

Based on the Greek myth of Circe, Devkota has composed an epic, Mayavini Sarsi. He begins the story invoking the god, Neptune and remembering many other gods and goddesses. Structured in five sections, the first section presents the mental and physical preparation of the adventurous journey through the sea with a purpose of finding something meaningful in life, to conquer over something, though not certain what it is, different from the normal life experience. The central character and the heroic figure, Ulysses tries to convince all the heroic members of the journey, the conquerors, to get victory over the fear:

Fear!

Victory over it is life,

Fighting with the ghost of death is life,

Victory over nature is self-philosophy,

Self-possession is great wealth. (Devkota 3$)^{1}$

The first section ends with hardship due to heavy sea waves and the conquerorstribute Jupiter, Mahesh and the goddess Saraswati at the time of their anxiety. They have felt it comfortable having the praise to these mythical Gods and Goddesses. 
Second section begins with the praise to Apollo on the second day of their journey, "Please Bhaskara, save us in our long and uncertain journey" (25). Ulysses suggests all his companions to be quite courageous. This leads them to recollect their courage. The third section describes their long and tiresome voyage with nothing as expected to surmount with. Ulysses agrees to take rest in any island they would come first, but it was only the next day that they came to an isle of Circe with sophisticated palace. It is in the same section the enchantress Circe has transformed the companies of Ulysses into animals. The fifth section provides the climax in the plot with Ulysses' visit with Circe, his dispute and victory over her and his action of reviving all his companions from their animal life and his way back to their hometown.

All through the action, Ulysses presents himself as the heroic character of all with good guidance, courage, good decision, strength and foresightedness, whereas Circe projects herself as a beautiful lady with the power of magic, but with an unfriendly and antagonistic nature though "it is better to suppose her as a central character because of her role of making the plot living" (Neupane 276), which, as Devkota has given the title from her name, appears to be justified. The plot, Ulysses releasing all his companies from their animal life and ignorance, ends in a comic mode.

\section{East-West Mythical Reworking}

Applying the western mythical story of Circe in his epic written in Nepali, Devkota has combined both eastern and western mythical references however differences do exist in them.

\section{Krishna's Karma Principle in Ulysses}

Influenced by Greek mythical picture of Circe from Homer while being in Varanasi, Devkota has taken the character and foundation of the plot of Mayavini Sarsi from the same story. He has not presented the story just as it is; rather he has reworked with it to make itidentical to Nepali or eastern savor with slight difference even in the mode of the story. He has taken the characters and the setting from Greek mythical context, but he has mixed up with eastern mode of experiencing the life,

fighting is the training of life

.......

great heroes,

began to sing the songs in the boat

with happiness and joy like in Krishna's

Kurukshetra the song of the theme of Gita.

(Devkota 12)

The hero travellers were from Greece, but they had the experience of the east and the eastern mythical realization, their happiness was similar to that of the soldiers of Kurukshetra, their song was like the song from Gita matching with the selfless action of life. By doing such, he has given the western situation, sea location, boating, sea waves, but with eastern feeling. Ulysses convinces his fellow travellers to continue 
their journey even in the risk of life in the way Lord Krishna does toArjuna to go fighting, "Jatasya hi dhruvomrityurdhrumjanmamritasyachha" (Gita. 2. 27) (one who has taken his birth is sure to die and after death one is sure to take birth again). Ulysses follows the same way of the certainty of death, "it is the destiny of man from the god that life ultimately ends in death" (Devkota 12),.... "facing the Risk is divinity" (13).

Ulysses encourages his fellow travellers to fight in every danger they come across, “...

... fight, fight the heroes, one thing will certainly be achieved when the soul leaves the body" (16). He provides the lesson of getting something even in the separation of body and soul. Similar views are present in Krishna's morals to Arjuna,

"hatovaprapsyasiswargamjitysvamokshyasemahim, tasmaduttisthakaunteyayuddhayakritanischaya" (Gita 2.

37.)

(O son of Kunti, either you will be killed in the battlefield and attain the heavenly planets or you will conquer and enjoy the earthly kingdom.

So, get up with determination and fight.)

Ulysses, in this context encourages his fellow travellers to fight with the nature and natural disasters on their way. The message is that, every fighting leads to some achievement, even in death, there is the achievement.

Known to the mystery of life, uncertainty in the journey, and life and death as the essence for the beings, Ulysses follows karma principle of Gita as provided by the Lord Krishna. Karma makes man great. Ulysses supposes the life full of power in the path of karma, especially the selfless karma. The selfless karma makes no harm in life,

Is it the great heroism,

Endless going of the traveller with great aim?

the death itself is the heaven in the great aspiration (Devkota 33).

Gita's karma theory supposes the happiness and sadness as the same or the one, "shukhadukhe same krittwalaabhalaabhaujayajayau,

tatoyuddhayayujyaswanaibampaapamavapyasi" (Gita 2. 38).

(you fight for the sake of fighting without considering happiness or sadness, loss or gain, doing so you shall never be in sin.)

Seeing no difference between life and death, Ulysses feels the life in death, death as the heaven and death as the achievement in the mode of difficult ambition, the great Karma in life, "we are the war skilled in the workplace (Karmakshetra)" (Devkota 18). Karmakshetra represents, for the people in war, for Kurukshetra. The war, here, is the karma, the one with no desire, no hope for the outputs, but just as the duty of life, only for those who have something different wish from others. A man with the sense of karma in life does not have fear over the death, neither the desire for death, but the desire of the victory far beyond the physical desire of the life and pleasure. 


\section{Rig Vedic Surya Image in Apollo and Neptune}

The book begins from the praise/ invocation of Neptune and frequently referred as the god, Varuna. Second section of the book, Mayavini Sarsi begins with the praise to Apollo, as all the Greek travellers including Ulysses invoke Apollo for the success and prosperity of life,for Greeks recognize Apollo as a god of archery, music and dance, truth and prophecy, healing and diseases, the Sun and light, poetry, and many more.

Ounfinished youth full of light,

sky traveller,

Seabird with goldenwings

.....

Namaskaara to the world-viewer

On our endless journey,

Save us, Oh Bhaskara! (Devkota 24-25)

Ulysses and his fellow travellers have strong faith on Apollo. They expect their day be happy keeping the image of Apollo within them. Similar picture of Surya as the god of power, energy, prosperity and happiness is found in Rig Vedic picture:

"Yenasuryajyotishabadhasetamojagachchavishwamudiryasibhanuna" (RV. 10.

37. 4) (With that light Surya, you despise the darkness, you quicken every morning, remove from us all famine, neglect of oblations, sickness and evil dreams....

Grant us Surya various wealth where by we may prosper on the road and in the house).

With the image of the Apollo as the god of light and power, this image resembles to the Vedic image of Surya. The day begins with Surya, life activities are conducted with Surya, creativity flourishes with Surya, the journey takes place with Surya and the life becomes possible with the energy given by Surya. So, Surya is worth praised, and so do the Greek travellers in the epic naming the God as Apollo or Bhaskara and feeling the sense of Surya.

\section{Diana and Saraswati in Sarsi}

Devkota has visitedresemblance in eastern and western mythical pictures of Circe, Diana and Saraswati, both in their physical and behavioral features. Circe, the daughter of Helios and goddess of magic, and a beautiful enchantresscontinues to be one of the most enchanting deities of ancient Greek mythology.

Similarly, in Roman mythology, Diana is the goddess of the woodlands, of wild animals, and of hunting. She also acts as a fertility goddess, who helped women conceive and give birth to children. With many associations, as goddess of forests and hunting, she is considered to be pure and virgin. Yet she could also be arrogant and 
vengeful. As goddess of the moon, she has a changeable, unpredictable nature. As goddess of the dark world of the dead, she is unforgiving and bloodthirsty.

Similarly, Saraswati, goddess of knowledge and the arts, in Hindu mythology, embodies the wisdom of Devi. She is the river, (in the Rig Veda) of consciousness that enlivens creation; she is the dawn-goddess whose rays dispel the darkness of ignorance. Without her there is only chaos and confusion. To realize her, one must go beyond the pleasures of the senses and rejoice in the serenity of the spirit. She embodies all that is pure and sublime in Nature.

Devkota has seen the combination of Diana and Sarasawati in Sarsi (Circe) in her beauty, appearance and the power as the goddess:

\section{Carrier of Vina Apollo goddess Sabita}

Moved on the way singing songs

Goddess Diana

Purvodbhasini

Shikhararohini (Devkota 52)

Like that of Saraswati, Sarsi has got Vina on her hands and she is playing it when she appears in front of the animals. She has the power of speech, brightness, and cheers the creatures. As the goddess of wild animals and woodlands, Diana, Sarsi enjoys her life with animals, feels pity to them, and likes their obedience, their innocence.

Similarly, he has seen similar images between goddess Saraswati and goddess Minerva

"Yes, prosperous from the heaven,

Yes, Minerva, Saraswati with Vina" (9).

With these images of Saraswati, Diana, Minerva and Sarsi, the poet has deliberately brought the connections in their features with the conclusion that myths, as the common and universal property, may pass everywhere no matter the change it may take place.

\section{DevkotaRevisiting Circe in Mayavini Sarsi}

Derived from Greek mythical reference, Mayavini Sarsi is Homer's Circe in Odyssey. Devkota has introduced Sarsi in the third section as a 'nymph Sarsi with Grecian face' (Devkota 37). She is presented as a beautiful and clever lady. She has well managed palace, sophisticated lifestyle, and good manner of welcoming the guests, "Can we provide slight welcome to you gentle Grecian heroes on this poor house" (38). She has the magic power of managing everything herself. She just thinks, and orders on the air and everything appears as she has no men to serve, "when she raises her hand, the glasses with red wine appear in the air" (41). She proves herself as a real enchantress. She appears to be friendly, hospitable, cordial and gentle at the beginning, but she turns out to be quite ill-disposed and unfavorable as the story moves on. She has the interest to enjoy herself in transferring humans into animals and 
observing humans in animal form. Slightly differing from the original myth of Circe transferring all Grecian Heroes into pigs, Devkota has given a change in the story that Circe has transferred all Ulysses's hero travellers into different kinds of animals using her spell, "Pashubhava, pashubhava" (44). They have become pigs, goats, he-goats, lamb and donkey.

It is a strange matter that all of them have become animals in their behaviour, but they have human mind. They are happy on their situations of being animals. They have felt lucky themselves seeing her beauty and obeying, "Circe nature beauty, chewing grass on her command, the life full of wealth" (46), "you splendor lady, how beautiful life you have given to us" (48).All these animals have forgotten their previous life as human beings, they have accepted their predicament, but still they can think, feel and speak. This level if human-animal mixedness has the irony to humanity.

Myth does not need to come as original in conveying the same mythical message in the successive literary writings, "the specific combination of the elements of myth will vary from myth to myth, but the way of producing this combination is unique to myth and universal" (Buchanan 328). The variation occurs deliberately or reflexively, Myths are "timeless or simultaneously historical and ahistorical" (328). Unlike poetry, myths "can be translated from language to language, from one type of media to another without loss of coherence or consequence, and thus, there is no such thing as the true or original form of myth" (328). With this condition of translation and transformation, the myth of Circe has come to Nepalese context and Nepalese language.

Ending differently from the original myth of the queen Circe, Devkota has reworked to give didactic tone. Original myth relates Ulysses getting overpowered by Hermes on how to resist Circe's magic spell, but Devkota has presented Ulysses as a self conscious, courageous, and decisive man who does not drink the drink given to him by Circe. Similarly, the original myth shows Ulysses accepting Circe as his beloved and spending a year with her, but Devkota has changed this mode with Ulysses as responsible character overcoming Circe with his power.He has revived his fellow travellers into their human life from their animal life, "Om narabhavanarabhava!" (Devkota 67).Having their human life returned, they still need to have their humanity back, which Ulysses pleads for,

animals move back to own nation,

control your desire and lust,

control your animalism

which makes

the destruction of humanity (67),

and their journey begins back to their nation with the ending of the story.

Hence, having the knowledge of Greek mythologies, Devkota has handled the myth of Circe in the epic carefully. Adopting the theme of the myth, he has tried to present it as connecting with eastern mythical references. Giving eastern flavor has resulted in some changes in the original mythical order. 
Sarsi, Animal Symbols and Political Satire

Pigs are the only animals featured in the original Circe myth. With many symbolic meanings attached to it, pig refers to a number of connotations. As a laid back animal it does not easily attack or angered, but chooses to enjoy life. It symbolizes prosperity, wealth and abundance. The Pig is thought to bring luck to farmers as it brings in a good crop as well as rains. The pig is a powerful symbol as it brings all these good things. Animals feature largely in the epic, for Circe's famous for her ability to transform men into animals with a glass of drink. In this poem, she draws a distinct connection between animals and humans, arguing that there are times when humans behave like animals, and in those cases, she just helps them by making them look like the animals they mimic.

Not only pigs are portrayed in the epic. The travelling heroes are converted into lambs, goats, donkeys and he-goats. All these animals are the meek animals having no power as such. They symbolize for the helplessness. Further more, they have no reactions against Sarsi. They are just the followers of Sarsi. They are given the grass, they are provided with the greenery they wish and they are tempted with the beauty of the lady. They are controlled, dominated, victimized and silenced. At the same time, Sarsi is presented as the powerful lady, more powerful than anything else in the island.

All this picture of Sarsi and the animals has some connection with the contemporary political situation of Nepal for which Devkota was aware of. Sarsi symbolizes for the cruelRana power, where as the meek creatures/ animals are the symbols of common people. The whole epic, in this sense, can be understood as the silent but strong satire to the Rana dictatorship. Sarsi is the symbol of autocrat ruler.And her activity of making humans animal is how the rulers of that time behaved the common people as the animals. Ulysses' revolt and success of freeing his fellow friends indicates to poet's desire/ keen interest towards freedom.

\section{Mayavini Sarsi Remaking Myths}

Mythsare always moving and lively. As the collection of the stories passing through generations, myths provide the foundation to literary creation. Authors borrow the mythical stories to portray, examine and evaluate the contemporary society and the experiences of life. There are mainly two ways authors use the myths in their writingsputting the mythical stories in the literature as original without giving any change, and reshaping and setting the mythical stories to contemporary experiences. In both conditions, the myth moves and gives lively picture of the past at present and to future.

Likewise, Devkota has reworked with the western Grecian myth of Circe in Mayavini Sarsi making respective connection with eastern mythical references of Krishna, Saraswati, Surya, Varuna with western mythical references of Circe, Minerva, Diana and Ulysses. He has done it in two ways- bringing the mythical plot and picture as it was and making deliberate changes to make parallel link and to analyze the contemporary context, especially Nepalese politics- Rana brutality over citizens and its treatment to people as animals. 


\section{Works Cited}

Baldick, Chris. Oxford Concise Dictionary of Literary Terms. New Delhi: Oxford University Press, 2006. Print.

Bell, Michael. "Anthropology and / a Myth in Modern Criticism" Literary Theory and Criticism. Ed. Patricia Waugh. New Delhi: Oxford UP, 2006. Print. (119-129).

Bhagavad Gita As It Is. Mumbai: The Bhaktivedanta Book Trust, 1986. Print.

Buchanan, Ian. Oxford Dictionary of Critical Theory. New York: Oxford UP, 2010.

Print.

Childs, Peter and Roger Fowler. The Routledge Dictionary of Literary Terms. London andNew York: Routledge, 2008. Print.

Cuddon, J. A. Dicionary of Literary Terms and Literary Theory. New Delhi: Penguin Books, 2010. Print.

Devkota, Laxmi Prasad. MunaMadan. trans. Padma Devkota. New Delhi: Adarsh Books, 2018.

Print.

Devkota, Laxmi Prasad. Mayavini Sarsi.ed. Mohanraj Sharma. Varanasi: Nepali SahityaGhar, 1967. Print.

Joshi, Kumar Bahadur. DevkotakaKabitakritikoKaalakramikVivechena (Chronological Analysis of Devkota's Poetry). $2^{\text {nd }}$ ed. Lalitpur:

ShajhaPrakasan, 2067 BS. Print.

Neupane, Netra Prasad. DevkotakaKritimaManavatabaad (Humanism in Devkota's Writings).

Kathmandu: Aashish Books, 2067 BS. Print.

RgvedaSamhita. trans. H. H. Wilson and ed. Ravi PrakashAryaand K. L. Joshi. 2nd ed. 4 vols.

Delhi: Parimal Publications, 2001. Print. 